\title{
Biloculate false aneurysm of the right ventricle after cardiac surgery
}

\author{
A. A. R. Samarrai, R. McCloy, and M. B. Ablett \\ From the Hammersmith Hospital, London WI2
}

$A$ case of a 12-year-old boy who had double false aneurysms of the right ventricle after incomplete closed pulmonary valvotomy six years earlier is presented. The aneurysms were successfully treated surgically, and the aetiology is discussed.

False ventricular aneurysms are a rare and potentially fatal complication of cardiac surgery. They are less common than true aneurysms (Hurst, Fine, and Keyes, 1963; Littler, Meade, and Hamilton, I97 I ; Rosenthal, Gross, and Pasternac, 1972; Van Tassel and Edwards, I972) but are more likely to rupture (Hunter and Benson, 1933; Gobel, VisudhArom, and Edwards, 1971; Van Tassel and Edwards, 1972; Rosenthal et al., 1972). Both types of aneurysms are more frequent sequelae of operations on the left ventricle (Littler et al., 197I).

This report describes what we believe to be a unique case of a patient who, after a closed pulmonary valvotomy, developed a false right ventricular aneurysm. This aneurysm, in turn, had ruptured into the left pleural cavity, resulting in a second false chamber. The patient survived this event and surgical correction of the lesion followed successfully.

\section{Case history}

A 12-year-old West Indian negro boy was born normally at full term. His mother had had rubella in the first month of pregnancy, and a heart murmur was discovered when he was 3 months old. He failed to thrive and was prone to upper respiratory tract infection. In 1967, at the age of 5 years, the diagnosis of pulmonary stenosis was made, and a transventricular pulmonary valvotomy was performed through a left thoracotomy. Apart from transient early postoperative pulmonary collapse and infection he maintained a gradual progressive improvement. Three years later he experienced slightly reduced exercise tolerance. In May 1973 a routine chest radiograph disclosed a widened mediastinum and a large round opacity in the upper left lung field. A right ventricular aneurysm was suspected. Two months later he was referred to the Hammersmith Hospital. His only symptom was a slightly reduced exercise tolerance.

On examination he was a thin, fit young boy. His arterial pressure was $110 / 80 \mathrm{mmHg}$ ( $14.6 / 10.6 \mathrm{kPa}$ ), his pulse rate 100 per minute and regular; the jugular venous pulse was $2 \mathrm{~cm}$ above the sternoclavicular joint, with a prominent ' $a$ ' wave. There were distinct visible pulsations at the second and third left intercostal spaces. A grade $4 / 6$ ejection systolic murmur was heard at the pulmonary area, with grade $3 / 4$ pulmonary diastolic murmur. There were no signs of heart failure, and the previous thoracotomy was well healed, with a keloid scar. Routine laboratory investigations were normal. The chest radiograph showed a large right ventricle and slightly oligaemic lung fields. A large rounded shadow was superimposed on the main pulmonary artery and extended, just above it, into the upper left lung field. The lateral view showed anteroposterior extension of the mass (Fig. I).

The electrocardiogram showed right axis deviation and right ventricular hypertrophy.

Cardiac catheterization disclosed a residual gradient of $60 \mathrm{mmHg}(8.0 \mathrm{kPa})$ across the pulmonary valve: MPA pressure $30 / 13 \mathrm{mmHg}(4.0 / 1.7 \mathrm{kPa}), \mathrm{RV}$ body $90 / 21 \mathrm{mmHg}(120 / 2.8 \mathrm{kPa})$, pressure within aneurysm $89 / 15 \mathrm{mmHg}$ (Ir.8/2.0 kPa).

The cineangiocardiogram of the right ventricle showed a centrally placed mediastinal aneurysm above and anterior to the heart, which filled by a jet from the right ventricular infundibulum. This mediastinal sac, in turn, communicated with and filled a posterolaterally placed sac in the left pleura. 


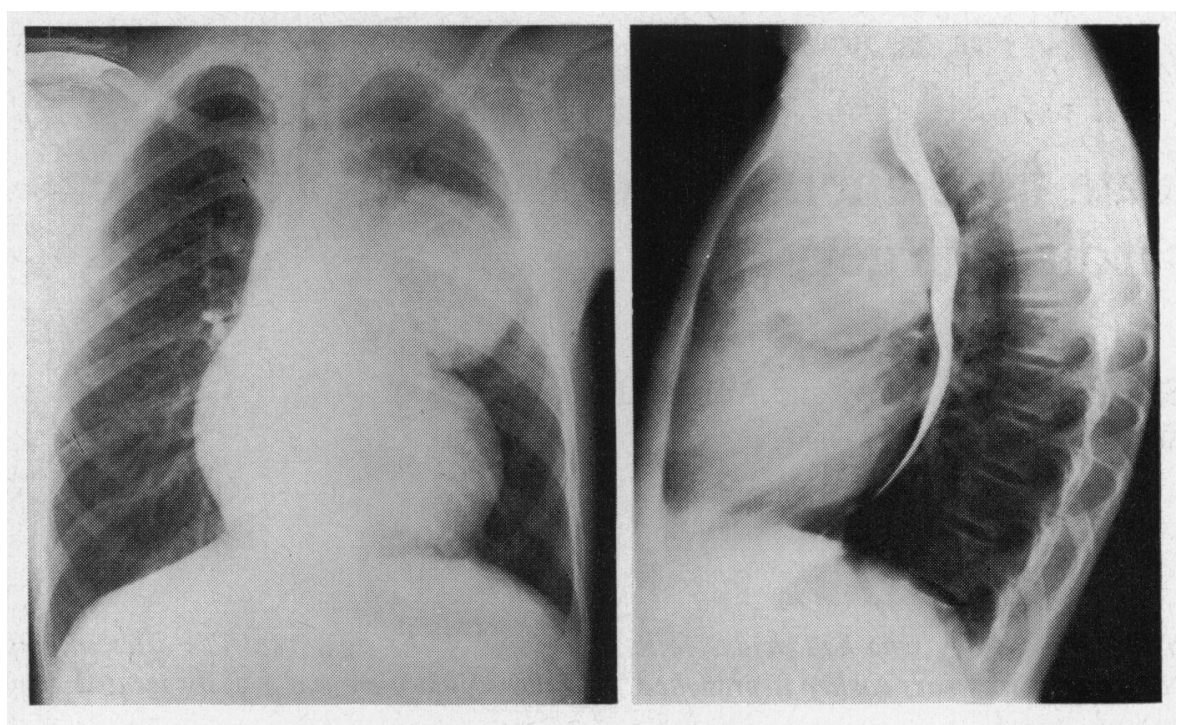

FIG. I Preoperative posteroanterior and lateral chest radiographs showing a large right ventricle, and a large rounded central shadow superimposed on the pulmonary trunk and extending to the upper left lung field. The mass extends antero-posteriorly on the lateral view.

The main pulmonary artery was displaced backwards and was compressed by the mediastinal aneurysm. No communication could be demonstrated between the pulmonary trunk with its two branches and either of the two aneurysmal sacs. Injection of contrast medium into the superior vena cava disclosed the close proximity of the juxta-atrial part of the superior vena cava and of the right atrial appendage to the mediastinal aneurysm. The appearance was that of a fairly large right ventricular aneurysm communicating with a second aneurysmal chamber in the left pleura.

\section{Operation (H.H.B.)}

In view of the angiographic findings and the intimate relations of the superior vena cava and the right atrial appendage to the central aneurysm sac, the risks involved in using a median sternotomy approach were appreciable. The right femoral artery, therefore, was cannulated, and a right anterolateral thoracotomy was performed through the fourth intercostal space. This approach provided trouble-free access to cannulate both cavae. Total cardiopulmonary bypass was established, the mediastinal aneurysm was freed from the back of the sternum, and the sternum was then divided transversely. The aneurysm was a false sac formed by the pericardium. It was opened anteriorly and found to communicate with the right ventricular infundibulum through a $1.5 \mathrm{~cm}$ elliptical hole, presumably the site of the previous ventriculotomy. Another $1.5 \mathrm{~cm}$ hole, laterally placed in the wall of the central aneurysm, led to the second false aneurysm formed by the adherent left pleura (Fig. 2). Neither cavity contained any thrombus.
The pulmonary trunk was incised longitudinally through the posterior wall of the mediastinal aneurysm to relieve the residual obstruction. The pulmonary valve was thickened, the commissures were fused, and the cusps were rolled in. It was evident that the pul-

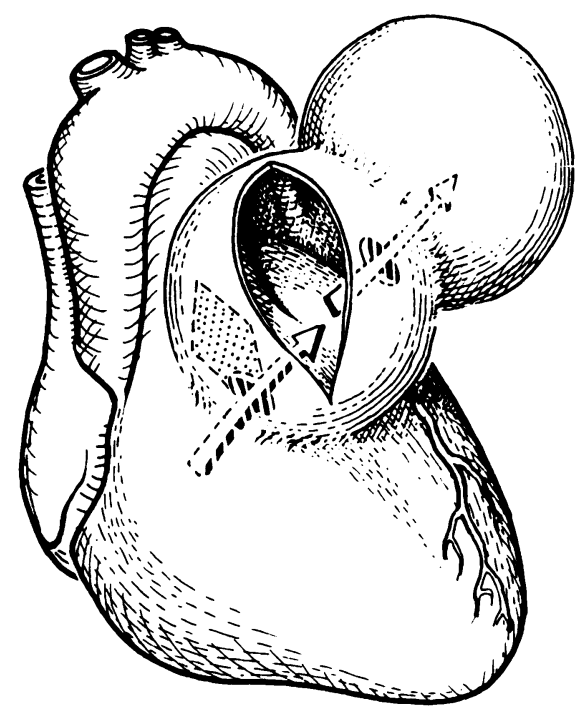

FIG. 2 A diagram demonstrating the sites and communications of the two aneurysmal chambers and the inserted Dacron patch to relieve the residual obstruction (diamond-shaped dotted area). 
monary valve was regurgitant, with severe residual stenosis.

The arteriotomy was then extended across the pulmonary ring down to the ventriculotomy dehiscence. Part of the pulmonary valve cusps were excised as well as some infundibular muscle. A diamond-shaped woven Dacron gusset was inserted to enlarge the outflow tract, pulmonary valve ring, and artery and to close the ventricular dehiscence. The central aneurysmal sac was partially excised and drained. The lateral aneurysmal sac was drained via its communication with the central sac, and the two drains were connected to an underwater-seal-suction system. The patient came off bypass uneventfully and the chest was closed routinely. The immediate postoperative chest radiograph showed residual left pleural thickening but otherwise was satisfactory. The child had a smooth postoperative course and was discharged home on 28 August 1974.

\section{Discussion}

The majority of the recorded false aneurysms of the heart are related to myocardial infarction or surgery on the ventricles (Hurst et al., 1963; Littler et al., 1971 ; Fadali et al., 1974). False aneurysms of the right ventricle are less common and follow surgery or trauma. Usually a false aneurysm follows a leak from the right ventricular outflow patch in the surgical correction of Fallot's tetralogy (Payne and Kirklin, I96I; Bahnson et al., I962; Wada et al., 1965), but, whether the ventriculotomy itself or the patch dehisces, the main aetiological factor is the persistence of residual outflow obstruction producing raised right ventricular pressure. This was certainly a factor in our case.

If the patient is to survive the right ventricular dehiscence, there must be coexisting pericardial adhesions to prevent fatal tamponade (Hurst et al., 1963; Stansel, Julian, and Dye, 1963; Fadali et al., 1974). A unique feature of this case is the further rupture of this fasle aneurysm into the left pleural space, which must have been limited by adhesions, a result of the previous thoractomy - hence the development of the second false chamber. There is no way of knowing whether this second rupture occurred simultaneously with the ventricular dehiscence.

This patient had a regurgitant pulmonary valve and a chest infection after the initial valvotomy. Both these conditions have been suggested by Hipona and Bloom (1965) as being possible factors in aneurysm formation. Other factors, in childhood, such as residual left-to-right shunts and complete heart block (Payne and Kirklin, 196I), congenital defects of the myocardium, traumatic myocardial necrosis, and Chagas's disease have also been blamed (Bahnson et al., 1962). On the whole aneurysms of the right ventricular outflow tract probably have a variety of causes.

Hurst et al. (1963) have suggested that the diagnosis of true versus false aneurysm cannot often be made preoperatively. However, our findings agree with Rosenthal et al. (1972) that false aneurysms tend to expand posteriorly and to the left upwards, and can reach a large size; and angiography in our case was strongly suggestive of false aneurysm.

Mirowski, Mehrizi, and Shah (1964) wondered whether the formation of keloid is in any way related to the development of ventricular aneurysm. They described a cardiac aneurysm at the site of right ventriculotomy in a patient with increased tendency to form keloid. It is interesting that our patient had developed keloid in his thoracotomy scar.

We agree with other authors in advising early surgery for false aneurysms. Indeed our patient was fortunate to come to surgery after surviving the development of double false aneurysmal sacs. The specifically designed surgical treatment helped to bring about the successful result (Jacobs, de Leval, and Stark, 1974).

Acknowledgment is made to Professor H. H. Bentall, Professor of Cardiac Surgery, The Royal Postgraduate Medical School, for permission to publish this report.

\section{References}

Bahnson, H. T., Spencer, F. C., Landtman, B., Wolf, M. D., Neill, C. A., and Taussig, H. B. (1962). Surgical treatment and follow-up of 147 cases of tetralogy of Fallot treated by correction. Fournal of Thoracic Surgery, 44, 419.

Fadali, M. A., Soulen, R. L., Sands, M. J., Jr., Lemole, G. M., and Kaplan, G. F. (1974). Successful surgical treatment of false ventricular aneurysm. Pennsylvania Medicine, 77, (February), 32.

Gobel, F. L., Visudh-Arom, K., and Edwards, J. E. (197I). Pseudoaneurysm of the left ventricle leading to recurrent pericardial haemorrhage. Chest, 59, 23.

Hipona, F. A., and Bloom, D. L. (1965). Postoperative aneurysm of the right ventricle. American fournal of Roentgenology, 95, 642 .

Hunter, W. C., and Benson, R. L. (1933). Rare form of saccular cardiac aneurysm with spontaneous rupture. American fournal of Pathology, 9, 593.

Hurst, C. D., Fine, G., and Keyes, J. W. (1963). Pseudoaneurysm of the heart, report of a case and review of literature. Circulation, 28, 427.

Jacobs, T., de Leval, M., and Stark, J. (1974). False aneurysm of right ventricle after Rastelli operation for transposition of great arteries, ventricular septal defect and pulmonary stenosis. Fournal of Thoracic and Cardiovascular Surgery, $67,543$.

Littler, W. A., Meade, J. B., and Hamilton, D. I. (1971). Ventricular aneurysms after cardiac surgery. British Heart fournal, 33, 962. 
Mirowski, M., Mehrizi, A., and Shah, K. D. (1964). Right ventricular aneurysm, a complication of transventricular pulmonary valvotomy. Report of two cases, one associated with gonadal agenesis. American Heart fournal, 68, 799.

Payne, W. S., and Kirklin, J. W. (196I). Late complications after plastic reconstruction of outflow tract in tetralogy of Fallot. Annals of Surgery, 154, 53.

Rosenthal, A., Gross, R. E., and Pasternac, A. (1972). Aneurysms of right ventricular outflow patches. Fournal of Thoracic and Cardiovascular Surgery, 63, 735.

Stansel, H. C., Jr., Julian, O. C., and Dye, W. S. (1963) Right ventricular aneurysm. A review of the literature and report of a case of successful repair with the aid of temporary cardiopulmonary bypass. Fournal of Thoracic and Cardiovascular Surgery, 46, 66.
Van Tassel, R. A., and Edwards, J. E. (1972). Rupture of heart complicating myocardial infarction. Analysis of 40 cases including nine examples of left ventricular false aneurysm. Chest, 6r, 104 .

Wada, J., Ideda, K., Kadowaki, Y., and Sugii, S. (I965). Right ventricular aneurysm following open cardiotomy for correction of tetralogy of Fallot. Annals of Thoracic Surgery, 1,184 .

Requests for reprints to R. F. McCloy, Esq., F.R.C.S., c/o Secretary, Cardiothoracic Surgery, Royal Postgraduate Medical School, Hammsermith Hospital, DuCane Road, London WI2 OHS. 